\title{
분쟁지역에서의 인도적 지원: 인도적 공간 사례 연구를 중심으로
}

장은하(한국여성정책연구원 부연구위원)

목 차

I. 서론

II. 이론적 검토

1. 인도적 공간의 정의

2. 인도적 공간의 제약

III. 인도적 공간의 확보: 수단, 아프가니스탄, 시리아 사례 분석

1. 수단생명선작전(Operation Lifeline Sudan): 협의체 구성을 통한 인도적 공 간 확보

2. 아프가니스탄: 인도적 원칙의 준수를 통한 인도적 공간의 확보

3. 시리아: 원격 관리(remote management) 및 현지 네트워크를 통한 인도적 공간의 확보

IV. 결론

I. 서론

최근 그 잔인성으로 국제사회를 경악케 한 ISIS의 참수 희생자들 중 대다수는 인 도적 구호 요원이었다. 영국인 앨런 헤닝(Alan Henning)은 생명구조와 관련된 의료 기기를 전달하는 임무를 수행하고 있었으며 또 다른 영국인 데이비드 헤인(David Haine)은 시리아에서 활동하는 프랑스 구호단체 소속 요원인 것으로 밝혀졌다. 2014 년 10월 현재 또 다른 참수 위협 동영상에 등장하고 있는 미국인 피터 카시그(Peter 
Kassig)는 인도적 지원 단체의 대표로서 시리아 난민을 돕고 있었다. 이는 최근 증 가하는 인도적 구호요원 피해의 단편적 사례에 불과하다. 2013년 한 해 동안 전 세 계적으로 460 명의 구호요원이 피해를 입었고, 그 중 155 명이 사망하고 171 명은 심각 한 부상을 입었으며 134 명은 납치되었는데 희생자의 대부분은 지원을 실행하는 지역 $\mathrm{NGO}$ 직원이나 적십자 요원이었다(Stoddard, Harmer and Ryou 2014:1). 이는 2003년 피해규모인 87명의 사망자, 49명의 부상자, 7명의 납치희생자와 비교할 때 매우 큰 증가이다(Stoddard, Harmer and Ryou 2014:1).

이러한 현상은 인도적 공간의 확보 여부와 연관이 있다. 인도적 공간이란 인도적 지원 활동이 이루어질 수 있도록 비폭력과 안전이 보장된 공간으로 간략하게 정의할 수 있다. 분쟁의 양상이 국가 대 국가에서 내전으로 변화하는 현대전에서 인도적 공 간을 확보하는 것은 점점 어려워지고 있으며, 인도적 공간의 확보에 실패할 경우 지 원 물자 진입의 지연·불발뿐 아니라 인도적 구호요원이 희생되는 상황이 빈번하게 발 생한다. 2013년부터 특히 주목되는 현상은 인도적 구호요원을 대상으로 발생한 잠복 공격(ambush)이나 노상 공격(roadside attack)이 급격한 증가세에 있다는 점이다 (Stoddard, Harmer and Ryou 2014).

현재 한국의 경우 민간단체를 중심으로 수단 및 시리아 국경 지역 등에서 인도적 구호사업이 진행 중에 있다. 한국정부도 다자기구를 통해서 분쟁지역인 이라크, 팔레 스타인, 우크라이나 난민 지원 등을 지원하고 있으며, $\mathrm{OECD} \mathrm{DAC}$ 의 회원국으로서 인도적 지원을 확대할 것을 요구받고 있다. 그러나 소수의 국제 $\mathrm{NGO}$ 를 제외하고는 분쟁지역에 있어서의 인도적 지원 경험은 미비한 상황이며 특히 치안 및 안전지침 등도 견고히 마련되지 못한 상황이다. 현재 한국 정부와 단체들이 분쟁 당사국 내에 서 직접 지원활동을 벌이지 않는다 하더라도, 변이와 확산이 용이한 현대전의 성격 을 고려할 때, 분쟁에서의 인도적 지원의 양상과 위험에 대해 인지하고 대비하는 작 업이 필요하다.

이러한 배경 하에 본 연구는 먼저 인도적 공간의 개념에 대해 살펴본 후 분쟁에 있어서의 인도적 공간 확보에 있어서의 사례들을 살펴볼 것이다. 마지막으로 사례를 통해 도출한 인도적 공간 확보에 있어서의 시사점을 소개하고 분석한다. 본고를 통 
해 향후 한국 정부와 단체들의 분쟁지역에서의 효과적이고 안전한 인도적 지원활동 에 미약하나마 도움이 되고자 하는 바이다.

\section{II. 이론적 검토}

\section{1. 인도적 공간의 정의}

인도적 공간을 하나의 개념으로 정의하기는 쉽지 않다. 인도적 공간을 설명함에 있어서 특정 조직의 철학과 활동 기준이 반영되기 때문이다(Von Pilar 1999; Brassard-Bourdeau and Humbert 2010). 아래에서는 인도적 공간에 관한 정의 중 대표적인 세 가지 관점을 검토하려고 한다(Collinson and Elhawary 2012).

제I장

제I장

\section{1) 지원 단체의 공간}

이 정의는 지원 단체들이 구호 활동을 수행하는 관점에서 인도적 공간을 설명한다 (Collinson and Elhawary 2012:2). 대표적으로는 인도적 공간이라는 단어를 1990년 대 초반 대중화시킨 국경없는 의사회(MSF)의 로이 브러먼(Roy Brauman)의 정의를 들 수 있다. 브러먼에 의하면 인도적 공간이란 "(인도적)니즈를 평가하고, 지원물자 의 전달과 사용을 모니터하고, 대화하는 데에 있어서 자유로운 공간”을 의미한다 (Collinson and Elhawary 2012: 1; Von Pilar 1999). 즉, 인도적 지원을 수행함에 있어서 정치적인 목적에 휘말리지 않고, 지역주민의 불신이나 저항 없이, 물리적 공 격으로부터 자유로운 독립적인 공간을 의미한다(Vautravers and Fox 2011:8). 유사 한 개념으로 “인도적 지원 수행 환경(humanitarian operating environment)" 또는 “인도적 통로(humanitarian corridor)”가 있다.

인도적 공간의 확보를 위해 구호 단체는 비정치성, 독립성, 중립성, 공평성의 관점을 견 지해야 한다(Salera 2011). 첨예하게 대립하는 분쟁 지역에서 지원 기관이 어느 한 편을 든다거나, 공평하지 않은 방법으로 지원을 수행할 경우 인도적 공간은 위협에 처할 수 있 기 때문이다. 인도적 공간을 "인도적 활동 환경(Humanitarian Operating Environment)" 으로 지칭하는 UN의 설명은 이러한 관점을 반영하고 있다(UN OCHA 2003). 
“중립과 공평의 원칙을 지키는 것은 고통을 경감시키는 목표를 달성할 수 있는 주요 수단이다. 따라서 군사적 행위와 인도적 활동의 역할과 기능을 명확히 구 분하는 것은 지원 단체들이 효율적이고 안전하게 책임을 수행할 수 있는 인도 적 활동 공간 조성에 있어서 결정적 요인이다. 인도적 지원이 조건적이지 않 고, 분쟁의 한 편을 지원하지 않으며, 군사적·정치적 활동으로부터 독립적일 때 지속적인 접근은 보장된다(UN OCHA 2003)".

이 설명을 통해 확인할 수 있는 또 다른 점은 인도적 활동과 군사적 활동을 구별 하는 것이 인도적 공간의 확보에 있어서 매우 중요한 요인이라는 것이다. 즉, 지원 단체의 활동은 비정치적이고 비군사적인 인도적 활동임을 분쟁당사자와 지역주민에 게 분명히 인식시키는 것이 중요하다.

상기 $\mathrm{UN}$ 의 정의에서는 또한 독립의 원칙을 의도적으로 제외시키고 있음을 볼 수 있다. 이는 인도적 지원에 있어서도 해당 국가의 주권을 우선시하는 UN체제의 특징 에서 비롯된 것으로 파악될 수 있다(Boudreau and Hubert 2010).

\section{2) 지역사회의 공간}

이 경우는 인도적 공간을 정의함에 있어 단순히 인도적 지원이 이루어지는 제한적인 공간 뿐 아니라, 피해를 입은 지역사회에 초점을 맞추는 관점이다. 이는 인도적 니즈 를 충족함에 있어서 지원 단체의 활동 공간 뿐 아니라 피해지역 주민의 공간과 역할이 중요하다는 견해에서 유래하였다(Collinson and Elhawary 2012:2). 대표적인 인권기 반 국제 NGO인 옥스팜(Oxfam International)은 인도적 공간을 “보호와 지원을 받을 주민의 권리가 보장되는 활동 환경” 그리고 “피해주민의 니즈에 공평하고 독립적인 방 법으로 대응함으로써 효과적인 인도적 활동을 수행할 수 있는 활동환경”으로 정의하고 있다(Oxfam International, January 2008). 이는 수혜자의 인권을 강조하고 권리에 기반을 둔 지원을 강조하는 옥스팜의 철학을 잘 반영하고 있다. 또한 유엔난민기구인 $\mathrm{UNHCR}$ 도 인도적 공간이 단지 물리적 접근이나 구호요원의 치안만을 강조하는 것에 대해 반대하며 '보호공간' 및 '망명공간'과 연계될 것을 강조했다(Tennant, Doyle and Mazou 2011:32). 이 관점 역시 난민보호가 단체의 주요 임무인 UNHCR의 조직 철학 
을 반영하고 있다. 지역주민의 보호공간이 부재한 상태에서 지원 물자의 전달은 더 많 은 주민을 위협에 처하게 할 수 있기 때문이다(Tennant, Doyle and Mazou 2011:32).

\section{3) 국제인도법의 공간}

인도적 공간을 설명함에 있어서 국제인도법을 통해 조망하는 관점도 있다. 국제인 도법은 “인도적 공간”이라는 단어는 사용하고 있지 않으나, 여러 조항 내에서 인도적 공간의 의미를 포함하는 개념을 제시하고 있다(대한적십자사 2010). 전시에 있어서 민간인의 보호에 관한 제네바 제 4 협약의 3 조에서는 "국제적십자위원회와 같은 공정 한 인도적 기구는 충돌당사국에 대하여 그 용역을 제공할 수 있다”라고 무력충돌 상 황에서 인도적 지원 단체들의 활동을 허용하고 있다. 또한 동 협약 제 10 조는 민간인 보호와 구호를 위해 국제적십자위원회(ICRC)나 공평한 인도적 구호 기관이, 분쟁의 당사자의 동의 하에, 인도적 활동을 수행할 수 있음을 명시하고 있다. 비국제적 무력 충돌의 희생자 보호에 관한 내용을 담고 있는 추가의정서(제II의정서)의 여러 조항에 서도 인도적 지원과 관련된 내용이 발견된다(대한적십자사 2010).1) 여기에서는 민간 인 보호, 전투방법으로서의 민간인을 기아에 빠트리는 행위 금지(민간주민의 생존에 불가결한 식량, 농업지내, 수확물, 가축, 음수 시설 등의 목표 공격 및 파괴 금지), 분쟁 당사자의 동의 하에 민간인들에게 인도적 지원 허용 등을 명시하고 있다.

이러한 조항의 검토를 통해 알 수 있는 점은, 분쟁당사자들이 국제인도법을 준수 함으로써 분쟁의 한복판에서 인도적 공간이 확보될 수 있다는 점이다. 바꾸어 말하 면, 무력충돌의 당사자들이 국제인도법을 준수할 수 있게 장려하고 촉구하는 것을 통해 인도적 공간이 확보될 수 있으며 이러한 측면에서 국제인도법은 유용한 수단이 될 수 있다. 또 한 가지 언급할 사항은, 국제인도법상의 인도적 공간은 앞서 설명한 지원단체의 활동공간보다는 광의의 개념이다. 왜냐하면 무력충돌의 양 당사자를 개 입시킬 뿐 아니라 이들에게 민간인 보호를 위한 법적 의무와 제약을 부여하기 때문 이다(Collinson and Elhawary 2012: 2).

1) 1949년 8월 12일자 제네바 제협약에 대한 추가 및 비국제적 무력충돌의 희생자 보호 에 관한 의정서(제의의정서)의 7 조 - 12조(의무업무에 대한 기술), 18 조(구호단체 및 구호활동), 11 조(의무부대 및 수송수단의 보호) 등 참조(대한적십자사 인도법 연구소 2010) 
국제인도법의 관점에서 인도적 공간을 조망하는 것은 인도적 공간의 확보에 있어 서 몇 가지 시사점을 던져 준다(Collinson and Elhawary 2012: 2). 첫째, 인도적 공간은 단지 구호 뿐 아니라 민간인 보호도 포함해야 한다는 사실이다. 국제인도법 은 민간인 보호에도 중점을 두고 있으며 이는 민간인에 대한 인도적 지원 뿐 아니라 보호를 할 수 있는 법적 근거를 제공하고 있다. 이는 앞서 검토한 난민 보호를 중시 하는 $\mathrm{UNHCR}$ 의 관점과도 유사하다. 둘째, 국제인도법은 인도적 지원 제공자 뿐 아 니라 해당 정부가 자국민 보호에 가장 우선의 책임이 있다는 점을 상기시키고 있다. 이는 인도적 공간 확보에 있어서 지원단체의 노력 뿐 아니라 무력 충돌의 당사자에 게 책임을 부여함으로써 인도적 공간의 유지를 더욱 공고히 할 수 있다는 점에서 의 미가 있다. 셋째, 인도적 지원 단체의 중립이나 독립에 관한 조항은 국제인도법 내에 존재하지 않는다. 그러나 중립을 지키지 않을 경우 해당 정부로부터 활동을 거부당 할 수 있다는 점을 상기시켜주고 있다. 국제인도법 상에서 인도적 지원은 해당 정부 의 동의 하에만 실시될 수 있기 때문에 분쟁의 어느 편도 들지 않는 중립원칙의 고 수는 매우 중요한 요인이다.

\section{2. 인도적 공간의 제약}

인도적 공간을 보다 이해하기 쉽게 도식화 하면 〈그림 1)과 같다. 1960년대 후반 의 나이지리아 내전은 물론, 1990 년대 소말리아 내전, 현재 시리아 내전 등 여러 내 전 상황을 이 도식으로 개념화할 수 있다. 아래의 그림은 앞서 검토한 인도적 공간 에 대한 여러 범위 중, 지원 단체의 공간을 중심으로 표현한 것이다. 수혜 지역사회 에 초점을 맞추거나 민간인 보호를 포함하는 국제인도법의 관점을 도입하면 인도적 공간의 범위는 단지 그림에서 보여주고 있는 인도적 통로(corridor)적인 성격보다는 그 범위가 훨씬 넓어질 수 있다. 


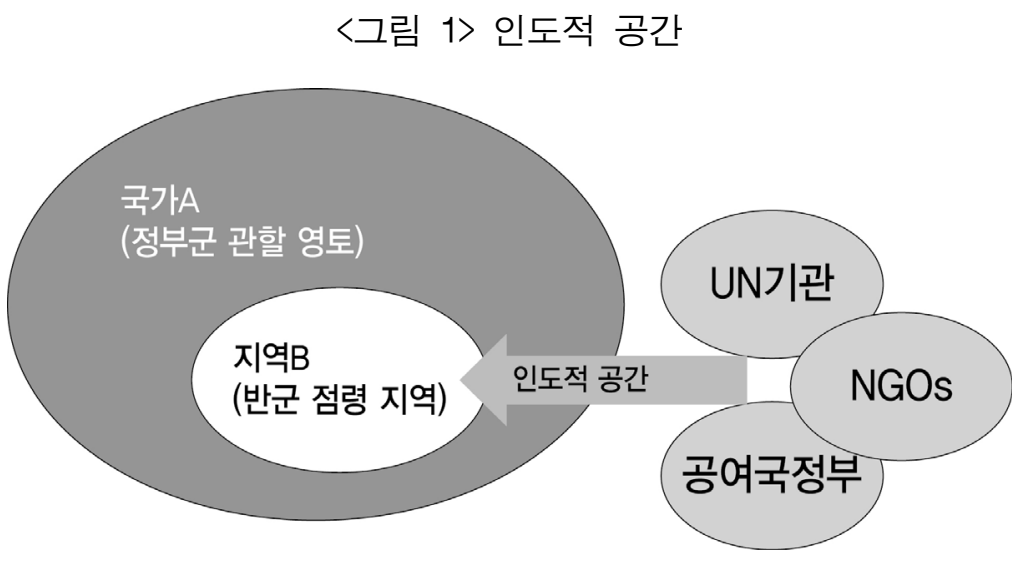

테넌트 외(Tennant, Doyle and Mazou 2011)는 인도적 공간의 확보에 영향을 주는 행위자에 대해 해당정부, 비국가행위자(non-state actor) 그리고 지역사회 행위자로 구분한다. 먼저, 정부가 인도적 공간을 제한하는 경우가 있다. $\mathrm{UN}$ 은 각국의 주권과 영토보전을 중시하는 국가중심의 체제이다. 따라서 $\mathrm{UN}$ 의 인도적 지원 활동에 있어서 도 피해당사국 정부가 주권을 행사하며 지원활동을 통제하고 조율하는 경우가 많다. 구체적으로는 구호 요원의 비자발급 지연, 특정 국적의 직원의 활동 거부, 직원 추방, 구호물자의 세관 통과 지연 및 거부 등의 행정적 제한을 부과함으로서 원활한 활동을 제한할 수 있다(Tennant, Doyle and Mazou 2011:38). 또한 자국 내 특정 지역 접근 거부, 보안 제약(security restrictions), 보호 장비 및 에스코트 요구 등의 인도적 활 동을 지리적으로 제한하는 경우도 있다(Tennant, Doyle and Mazou 2011:38). 현재 내전 중인 시리아의 경우가 이러한 예라고 할 수 있다. 시리아정부는 반군점령 지역 으로의 인도적 구호물자의 진입을 허용하지 않았으며 진입을 허용하더라도 여러 겹의 제약을 부과하고 있다. 이는 다음 장의 사례 연구를 통해 자세히 살펴볼 것이다.

다음으로 비국가행위자(non-state actors)가 인도적 공간을 제한하는 경우가 있 다. 이들은 자신의 점령지에 인도적 지원 단체의 접근 자체를 봉쇄한다. 2011년 UN 에 의해 기아가 선포된 소말리아에서 국토의 절반 이상을 장악하고 있던 알샤바브 (Al-Shabab) 반군이 점령지 내로 인도적 지원 물자를 허용하지 않은 것이 그 예이 다. 또한 인도적 구호요원을 겨냥한 고의적 공격 및 납치, 자신들의 가시성 (visibility)을 높이기 위한 국제기구 건물 등에의 테러, 인도적 요원의 안전에 대한 
위협 등을 포함하는 등 폭력적인 수단으로 인도적 공간에 위협을 가하기도 한다 (Tennant, Doyle and Mazou 2011:39).

마지막으로 인도적 지원활동이 이루어지는 지역사회 구성원들이 인도적 공간을 제한 하는 사례도 있다(Tennant, Doyle and Mazou 2011:40). 구호물자를 수혜 하는 지역사 회의 특정 개인이 사적인 목적을 위해 인도적 지원활동을 이용하는 경우, 지역사회의 대 표자(gatekeeper)나 난민촌의 리더들이 특정 프로그램을 거부하는 경우 등이 그 예이다.

\section{III. 인도적 공간의 확보: 수단, 아프가니스탄, 시리아 사례 분석}

본 장에서는 인도적 공간의 세 가지 사례를 살펴 볼 것이다. 분쟁의 당사자와 인 도적 지원 기관 간에 협의체를 구성하여 인도적 공간을 확보한 수단생명선작전 (Operation Lifeline Sudan, 이하 OLS), 중립과 공평의 인도적 원칙의 적극 준수를 통해 확보한 아프가니스탄 사례, 그리고 현재 진행 중인 시리아에서의 원격 관리 (remote management) 사례를 검토할 것이다.

\section{1. 수단생명선작전(Operation Lifeline Sudan, 이하 OLS): 협의체 구성을 통한 인 도적 공간 확보}

\section{1) 개요}

현재는 수단과 남수단으로 분리된 수단은 지난 세기동안 몇 차례의 내전을 겪었 다. 여기서 소개하려고 하는 수단생명선작전(Operation Lifeline Sudan, 이하 OLS) 은 수단 2차 내전(1983 - 1989) 당시 UN의 주도로 UN과 40여개의 국제기구, 수단 정부(GoS), 그리고 수단인민해방운동(Sudan People's Liberation Movement/Army, 이하 SPLM/A)이 1989년 결성한 삼자합의체(tripartite agreement)이다. 1988년 당 시 수단은 내전과 기아로 25만의 인구가 기아로 사망하였으나(Minear 2002: 89) 수 단 정부군과 반군은 인도적 구호가 필요한 지역에의 접근을 봉쇄한 상황이었다. 이 러한 배경 하에 UN은 OLS를 결성하여 수단정부군과 SPLM/A이 각각 장악하고 있는 지역으로 구호물자가 들어갈 수 있도록 설득하였다. 
OLS는 “협상을 통한 접근(negotiated access)”이라는 명칭 하에 인도적 지원이 필 요한 지역에의 접근 확보를 위한 협상을 진행하였다. UN, 수단정부, SPLM/A는 인 도적 원칙(중립, 공평) 준수, 삼자의 상호 의무, 구호 진행을 위한 제반 운영(장비 사 용, 직원 채용, 건물 렌트, 세금, 허가증, 구호요원의 안전) 등이 포함된 수행규칙 (Ground Rules)을 정하고 이에 합의하였다. 각 NGO는 수단 내 특정 지역을 책임 지고 그 지역 정부나 반군단체와 함께 협력하여 인도적 지원을 수행하였다 (Taylor-Robinson, 2002). OLS는 시행 초기에는 구호물자 전달 위주로 활동하였으 나 1993년 이후 남부 지역에서 개발협력으로 전환이 되었다. 즉, 단순한 구호식량의 전달보다는 식량안보측면에서의 개입, 생계지원, 인권 보호, 역량 강화 등의 프로그 램이 실시되었다.

\section{2) 긍정적 평가}

OLS는 몇 가지 측면에서 긍정적인 평가를 받았다. OLS의 가장 큰 의의는 분쟁이 진행 중인 주권국가의 영토 내에서 국내 실향민을 위해(국경 밖의 난민이 아닌) 이루 어진 최초의 인도적 프로그램이라는 점이다(Karim et al. 1996; Maxwell, Santschi and Gordon 2014). 즉, 국제인도법에서 명시하는 '비국제전(non-international conflict)' 내에서 수행된 최초의 인도적 구호이며, 국가의 권위에 도전하지 않고 주 권을 부분적으로 이양 받은 최초의 사례로서 인도적 대응의 영역을 넓힌 것으로도 평가받고 있다(Minear 1990; Maxwell, Santschi and Gordon 2014에서 재인용). OLS는 이후 이루어진 인도적 지원(앙골라, 이라크, 소말리아, 보스니아) 활동의 모 델이 되어왔다.

또한 분쟁 당사자들 간에 민간인 고통 경감과 지원에의 접근에 대한 공통분모를 찾기 위한 공간이 마련되었다는 점과, 구호물자 통과를 위해 합의된 “고요한 통로 (corridors of tranquility)"에서 실질적인 휴전이 이루어 진 점은 OLS가 가져온 예 기치 않은 부산물이었다(Maxwell, Santschi and Gordon 2014). 나아가 OLS가 분 쟁 당사자들에게 국제법을 준수하도록 도모하는 역할을 한 것도 긍정적인 측면이다. 수행규칙(Ground Rules)에 인도적 원칙을 포함함으로써 제네바협약의 조인국인 수 단정부가 국제인도법을 지키도록 촉구하였고, 협약에 조인하지 않았지만 SPLA도 이 
를 준수할 것에 대한 의지를 표명하였다. 마지막으로 정보 수집과 공유에 있어서도 타 활동보다 좋은 결과를 얻었는데, 이는 협상을 통해 피해지역에 접근이 가능하게 되었고 OLS도 프로그램의 여러 측면에서 정보 수집을 요구하였기 때문이다 (Maxwell, Santschi and Gordon 2014).

\section{3) 부정적 평가}

OLS에서 가장 큰 문제로 지적된 것은 접근과 지원에 있어서의 지역적 불균형이다 (Karim et al. 1996; Salera 2011:60-61). 수단의 북부는 정부군이, 남부는 $\mathrm{SPLM} / \mathrm{A}$ 와 군소반군이 점령하고 있었는데, 북부에서는 UN의 활동에 제약이 많았고, 남부에서는 UN의 활동이 좀 더 자유로웠다. 북부에서 OLS의 활동은 피해자들의 니 즈에 기반을 둔 것이 아니라 철저히 수단정부의 허락과 통제 하에 이루어졌으며 이 러한 상황에서 인도적 지원 단체들의 권한은 매우 제한적이었다. 남부에서도 정부 측이 주권을 한시적으로 포기한 일부 지역에서만으로 활동이 제한되었다(Karim et al. 1996). 피해자의 니즈에 기반을 두지 않은 지원은 OLS 수행규칙(Ground Rules) 에 명시된 공평의 원칙에 위배되는 것이다. 이러한 불균형으로 인해 1990년도 초에 이르러서는 OLS가 정부에게 특혜를 준다는 인식이 높아졌다(Salera 2011:60-61). OLS의 책임자가 수단 정부와 긴밀히 협력하고 있는 UNDP의 대표라는 점 또한 이러 한 의구심을 증폭시켰다(Karim et al. 1996).

이외에도 OLS는 긍정적인 평가보다는 부정적인 평가가 훨씬 많았다. 1996년 UN 에서 공식적으로 진행된 OLS에 대한 평가에서는 다음 사항들이 지적되었다(Karim et al. 1996). OLS의 주무기관(lead agency)인 UNICEF가 본연의 업무와 OLS 조율 및 프로그램 지원 업무를 모두 수행하기에는 무리였다. 또한 북부에서의 식량지원은 긴급구호에서 식량안보로 전환되었는데, 구호 종료에 대한 객관적인 평가 없이 개발 협력으로 이행이 된 점도 비판을 받았다(Karim et al. 1996). 남부 수단의 현지 파 트너들의 역량 부족도 문제로 지적되었다. 더불어 인권을 조건으로 지원이 제공된 점 또한 비판을 받았다. 인도적 지원의 불안정한 치안과 약탈의 문제도 지속적으로 제기되었다(Salera 2011:60-61). 이 평가는 OLS가 많은 문제를 안고 있으며 다른 지역에 적용되어서는 안 된다고(non-replicable)까지 지적하였다(Karim et al. 1996). 


\section{2. 아프가니스탄: 인도적 원칙의 준수를 통한 인도적 공간의 확보}

\section{1) 개요}

두 번째 사례로 1979 년 이후 30 여 년 동안 아프가니스탄에서 활동해 온 국제적십 자위원회(이하 ICRC)의 활동을 살펴보려고 한다. ICRC의 사례는 분쟁의 양 당사자 인 아프간 정부와 탈레반 및 군소반군 집단을 대상으로 인도적 원칙, 특히 중립과 공평을 준수하는 노력을 기울임으로써 인도적 공간을 확보한 경우라고 볼 수 있다.

제 I장

제I장

국제적십자위원회는 2003년 아프가니스탄 남부 우루즈건(UrozgAn) 주(州)에서 국 제적십자 요원이 반군의 총기 공격에 의해 사망하는 사건 이후 “인도적 공간”을 확보 하기 위한 적극적 노력을 기울이기 시작하였다(Terry 2011:175 - 181). 분쟁 상황에 서 인도적 접근을 확보하기 위해서는 분쟁 양측의 신뢰를 얻는 것이 선결 조건이다. 이를 위해 ICRC는 탈레반 및 군소반군들과의 대화 통로를 열었다. 미군기지 내 구치 소에 수용된 반군과 그 가족들의 연락을 주선했고, 반군 부상병에게 진료를 제공했 다. 또한 탈레반의 요새인 칸다하르 지역의 현지 택시 운전사들을 고용하여 응급처 치 교육을 시킨 후 해외구호요원으로서는 접근이 어렵고 위험한 지역에서 발생한 부 상병들을 병원으로 후송하는 임무를 맡기기도 하였다(Terry 2011). 이는 적십자 표장 이 더 이상 안전을 보장해 주지 못하는 상황에서, 공격에의 위험이 덜 한 현지인 기 사가 운전하는 택시를 “인도적 공간”으로 탈바꿈한 창의적 접근 방법이다.

그러나 반군들을 위한 적극적·인도적 지원은 이번엔 아프간 정부의 반발을 사게 되 었고, 국제적십자위원회는 아프간 정부를 위해서도 설득과 지원을 지속하였다. 2009 년 국제적십자위원회는 탈레반에 의해 수용되어 있는 아프간 정부군들의 생사를 확 인하여 가족들에게 안부를 통보하였으며, 포로로 수감된 것으로 추정되는 미군의 신 병 확인을 위해 탈레반과 지속적인 협상을 벌이는 등 정부군을 위해서도 중립적 위 치에서 적극 활동하였다. ${ }^{2)}$ 그 결과로 국제적십자위원회는 아프간 정부와 카르자이 대통령에게서도 신뢰를 얻게 되었다(Terry 2011:182).

2) Al Jazeera. "Red Cross Visits Taleban Captives" 2009. 12. 16. http://www.aljazeera.com/news/asia/2009/12/2009121661730958514.html (접속일 2013. 1. 5.) 


\section{2) 성과}

국제적십자사의 중립과 공평의 원칙 수호에 기반을 둔 인도적 지원은 다음과 같은 결과를 가능케 하였다.

“[국제적십자위원회의] 중립적 위치는 반군 사망자의 시신을 가족에게 돌 려주고, 전염병 발생 시 감염자를 이송하고 구호물자를 전달 할 수 있도 록 전투를 일시 중단하는 절차를 가능케 해 준다. 2007년 이래로 우리는 아프간 보건부, 세계보건기구(WHO), 그리고 반군 간에 중재하는 역할을 담당해 왔는데, 보건부와 $\mathrm{WHO}$ 가 반군들의 공격에 대한 우려 없이 민간 소아마비 접종 프로그램을 수행할 수 있도록 협상을 중재해 왔다.” ${ }^{3)}$

이외에도 국제적십자위원회는 2009년 칸다하르의 콜레라 감염자의 치료와 수송을 위해서 미국과 반군 사이에 휴전을 요청했고, 휴전은 받아들여져서 환자들과 인도적 구호 요원들의 안전이 보장된 가운데 의료 지원이 이루어 질 수 있었다. 의료지원을 위해 양측이 일시적 휴전을 승인했다는 것은 인도적 공간 뿐 아니라 인도적 시간까 지 확보했다는 점에서 매우 큰 의의를 지닌다. ${ }^{4)}$

아프가니스탄에서의 국제적십자위원회의 중립원칙 수호와 인도적 공간의 확보는 매우 긍정적인 평가를 얻고 있다(Terry 2011; Egeland 2011). 에겔랜드(Egeland)는 “국제적십자위원회는 적극적이고, 효과적이고, 지속적인 접근 및 협상전략을 보여주 었다. 고위험 상황에서도 안전한 접근을 확보하였다"고 평가하였다(Egeland 2011: $3,22)$. 특히 국제적십자위원회는 아프간에서의 인도적 공간 확보를 위해 연간 500 번이 넘는 크고 작은 회의를 통해 만 명 이상의 분쟁당사자들과 접촉해 온 것으로 밝혀졌다(Egeland 2011: 22). 이러한 성과는 현대의 내전에서는 인도적 원칙이 적용 되기 어렵다는 주장을 일축하는 것이다(Brassard-Bourdeau and Humbert 2010).

3) "Afghanistan: ICRC maintains neutral, independent, humanitarian assistance." 2009. 11. 6. (아프간에서 활동하는 국제적십자 요원 인터뷰) http://www.icrc.org/eng/resources/documents/interview/afghanistan-interview-0611 09.htm

4) 이러한 인도적 휴전(humanitarian ceasefire)은 2014년 여름 이스라엘과 하마스의 무 력충돌에서도 여러 차례 실시된 바 있다. 


\section{3) 비난}

그러나 국제적십자위원회의 활동은 종종 비난을 받기도 하였다. 첫째, 탈레반을 돕 는 것은 적군의 편을 드는 것이라는 비난이다. 부시 행정부는 국제적십자위원회가 탈 레반에게 베푸는 인도적 행위를 적군의 편을 드는 것으로 간주하였다(Terry 2011:182-183). 일부 서방 공여국과 해당국 정부의 대(對)테러 정책은 개인이나, 구 호단체나 인도적 기관이 테러단체들에게 물자를 제공하는 것을 범죄행위로 규정하고 있다(Jackson 2012:3). 둘째, 국제적십자위원회가 탈레반 및 반군과 협상하고 인도적 지원을 제공하는 행위는 탈레반에게 합법적인 지위를 부여하게 된다는 비난이다 (Jackson 2012:3). 이는 내전 시, 인도적 지원 단체들이 피해 지역 접근을 위해 그 지역을 장악하고 있는 반군과 접촉을 할 때, 그리고 반군 점령 지역에 구호물자가 들 어 갈 때, 항시 제기되어 온 문제이다(Anderson 1999:50-53). 국제적십자위원회의 탈레반 지원에 대해서 심지어 고위 UN 관계자까지도 “합법한 측”과 “비난을 받아 마 땅한(reprehensible)한 측”에서 중립을 택할 수는 없다며 국제적십자위원회의 탈레반 부상병 및 민간인 지원에 대해 거세게 비난하였던 것으로 전해진다(Terry 2011:183).

\section{3. 시리아: 원격 관리(remote management) 및 현지 네트워크를 통한 인도적 공 간의 확보}

\section{1) 개요}

2011년 3월 내전 발발 이후 현재 3백만에 달하는 인구가 시리아를 떠나 주변국에서 난민으로서 생활하고 있으며, 6 백50만의 주민은 국내 실향민으로 전락하였다. ${ }^{5)}$ 시리 아 내부는 현재 인도적 지원이 절실히 필요한 상황임에도 불구하고 정부군과 반군의 교전 지역으로는 접근이 어려운 상황이다. 2014년 9월부터는 ISIS가 북부시리아를 공 격하고 점령함으로 인해 다시금 대량 난민사태가 발생하였다. UN안보리는 인도적 공 간을 확보하고자 2014년 7월 시리아의 인도적 접근을 촉구하는 결의안(2165)을 만장 일치로 채택하였다. 이는 UN과 협력기관이 시리아 정부의 동의 없이도 분쟁의 최전 방과 국경지역을 드나들며 지원물자를 전달할 수 있도록 허락한 조치이다. ${ }^{6)}$

5) UN OCHA Syria Webspage http://www.unocha.org/syria (2014. 11. 2 검색) 
UN OCHA(Office for the Coordination of Humanitarian Affairs) 시리아대표 를 지낸 벤 파커(Ben Parker)의 설명에 의하면 시리아에서 인도적 공간의 확보가 어 려운 주요 이유는 정부의 통제 때문이다(Ben Parker, 2013). 정부는 공식적으로는 시리아 전역에 있어서 인도적 지원 물자의 접근을 허락하고 있지만 실질적으로는 여 러 단계의 허가 절차를 요구하고 있다(Ben Parker, 2013). 예를 들면 현장에 구호요 원을 파견할 경우, 국적, 여권번호, 지위, 차량등록번호 등의 정보를 수일 전에 접수 시켜야 하고, 이것은 시리아아랍적신월사(Syrian Arab Red Crescent, SARC)로 보 내어 진다. 적신월사의 허가 후, 다시 외교부의 허가를 받아야 하며, 이후에야 비로 소 공식허가장이 발급된다. 구호차량은 이 허가장을 가지고 시리아 내부를 이동하게 되며 모든 검문소에서 이 허가장을 제시해야 한다. 구호차량은 정규 검문소 수색에 응해야 하며, 이외에도 불규칙한 검문이 이루어진다. 심지어는 검문소에서 구호 스태 프를 감금하고 지원물자를 약탈하는 경우도 있다. 또한 이들은 노상강도의 위험에 처하기도 한다. 이러한 절차의 복잡성과 이에 반하는 구호의 시급성으로 인해 몇몇 국제 구호 $\mathrm{NGO}$ 와 적신월사는 시리아 정부의 허가 없이 반군점령지역에서 일하고 있 으며 시리아 정부는 이들을 불법으로 간주하고 있다(Ben Parker, 2013).

\section{2) 성과}

정부의 통제와 교전으로 인해 공식적·인도적 공간이 부재한 시리아에서 활동 중인 인도적 지원 기관들은 현지 중소 규모의 $\mathrm{NGO}$ 를 이용하여 업무의 일부를 위탁하고 있다. 외국인으로서 언어적 장벽이 높고, 이로 인해 협상에 취약하며 그리고 현지 네 트워크가 미비하기 때문이다.

이에 더 나아가서 시리아 구호단체들, 국제 $\mathrm{NGO}$ 들, 적신월사는 반군점령지역에서 현지의 음성적 네트워크를 이용하고 있다. 특히 최근에는 통신 기술의 진보와 함께 등장한 “신세대" 현지 구호 요원에 의존하고 있다. ${ }^{7)}$ 이들은 개인적 연락망, 운전기사

6) UN 안보리 결의안 2165. http://unscr.com/en/resolutions/doc/2165 (2014.11. 2 검색)

7) AID POLICY: A "new humanitarianism" at play in Syrian crisis, IRIN: Humanitarian News and Analysis, 30 March 2012 http://www.irinnews.org/report/95209/aid-policy-a-new-humanitarianism-at-play-i $\mathrm{n}$-syrian-crisis 
및 밀수꾼 네트워크, 온라인 연락망을 통해 사선을 넘나들며 각종 인도적 물품을 전 달한다. 취재 및 의료서비스를 제공하고, 각종 물품을 밀수하며, 혈액을 포함한 의약 품을 의사들 네트워크에 전달하여 왔다. ${ }^{8)}$ 국제구호 단체들은 초기에는 이들의 활동 에 대해 의구심을 가졌으나, 현재는 비공식적으로 이들과 협력하고 있다.

\section{3) 문제점}

시리아의 현황과 같이 외국단체로서 접근이 어려운 지역에 현지 단체나 개인을 고 용하여 업무를 위탁하는 것은 모두 원격관리(remote management)의 한 종류에 해당 한다. 원격관리는 “접근이 제한된 지역에서 관리와 모니터링의 임무를 경험이 적은 (less experienced) 현지 직원이나 외부 파트너 기관에게 맡기는 것”으로 정의할 수 있다(Stoddard, Harmer, Renouf, 2010; Steets, Reichhold and Sagmeister 2012:54). 그러나 여기에는 세 가지 위험이 따른다(Steets, Reichhold and Sagmeister 2012:55-57). 첫째, 현지인에게 위험을 떠넘기는 것이다(risk transfer). 원격관리는 해외구호요원들이 들어갈 수 없는 지역에 현지인을 보내는 것이며, 여기 에는 현지인은 외국인보다 덜 위험할 것이라는 가정이 있다. 그러나 실제로 인도적 요원의 피해 가운데에는 현지인도 다수 포함되며 이로 인해 이 방식은 많은 윤리적 문제를 내포하고 있다(Brassard-Bourdeau and Humbert 2010). 둘째, 지원의 질이 저하될 수 있다. 실무진이 직접 현장을 보지 않고 현지인들을 통해 사업을 진행하는 것에는 사업의 질을 확인할 수 없다는 위험 부담이 따른다. 예를 들면, 현지인의 경 험미숙으로 인한 절차 상의 실수, 구호물자 검수 불가, 구호물자 유용 등을 그 예로 들 수 있다. 마지막으로 책무성의 저하이다. 원격 관리의 경우 모니터링과 평가의 과 정을 생략하는 경우가 많고 직접관리 감독이 어렵게 되는데, 이로 인해 공여기관에 대한 책무성은 저하되기 쉽다(Steets, Reichhold and Sagmeister 2012).

8) Ibid. 


\section{IV. 결론}

본고에서는 인도적 공간에 대한 개념을 검토하고 사례를 분석함으로써 분쟁에서의 인도적 공간이 무엇이며 이를 확보하기 위한 노력에는 어떤 방식이 있는지 검토하였 다. 수단생명선작전(OLS)의 경우 많은 비판과 논란에도 불구하고 협상을 통해 분쟁 중에도 인도적 공간을 확보할 수 있다는 점을 보여 주었다. 아프가니스탄의 사례는 적극적인 대화 노력과 중립과 공평의 인도적 원칙 준수를 통해 인도적 공간을 확보 할 수 있음을 보여 주었다. 시리아의 경우 원격지원과 현지 네트워크를 통해 인도적 공간의 확보가 가능하게 되는 것을 알 수 있었다. 이를 바탕으로 분쟁상황에서 인도 적 공간의 확보를 위한 절차와 시사점을 정리해 보면 다음과 같다.

먼저, 분쟁에서의 인도적 공간을 확보하기 위해서는 분쟁 및 현지 상황에 대한 철 저한 분석이 선행되어야 한다 $(\operatorname{Lim} 2011: 25)$. 많은 경우 구호요원들은 현지 문화, 관습, 언어에 대한 무지, 문화적 맥락에 대한 불충분한 이해, 이로 인한 부적절한 행 동으로 인해 무장단체들의 공격의 대상이 되거나 지원이 필요한 지역으로의 접근을 거부당하고 있다. 또한 정보수집 자체가 어렵고, 정보가 확보된다고 하더라도 잘못된 평가를 내리기 때문에 정확한 진단이 실패하는 경우도 있다(Brassard-Bourdeau and Humbert 2010; Gassmann 2005). 아울러 분쟁에 대한 연구, 즉 분쟁의 행위 자와 확산 양상을 정확하게 파악하는 것도 매우 중요하다. 이는 구체적으로 인도적 지원의 루트와 물자 전달 차량의 무장 정도 등을 결정하는 중요한 요인이 되기 때문 이다.

분쟁과 현지 상황에 대한 분석과 동시에 구호기관의 역량에 관한 냉정한 평가도 병행되어야 한다. 때로는 분쟁 지역에서의 인도적 지원은 한 조직의 역량을 넘어서 는 일이 될 수도 있다. 예를 들면, 분쟁지역 지원에서의 경험이 일천한 단체가 시리 아 국내에서 국내 실향민을 지원하는 경우이다. 또한 인도적 원칙이 심각하게 위배 되거나, 조직의 활동 범위에 제약이 심할 때에는 분쟁에 개입하는 것 보다는 평화를 위한 옹호활동이나 다른 위기 상황에 재원을 투입하는 것이 훨씬 더 효율적일 수 있 다(Slim and Gillard 2013). 
현지상황과 기관의 대응역량에 대한 분석 후에는 구체적인 지원의 방식과 루트를 결 정해야 할 것이다. 이 과정에서 구호 요원과 물자 이동 수단의 안전에 관한 지침을 수 립하고 실행하는 것이 점점 중요해 지고 있다. 구호단체를 눈에 띄지 않게 하기 위한 노력(예를 들면 물품에 부착된 단체의 표장 떼기, 현지 중고차량 이용 등), 무장 차량 사용, 방탄 시설 강화, 사설경호업체 고용 등의 시도를 하는 기관도 있다 (Brassard-Bourdeau and Humbert 2010). 또한 방어적 운전기술, 협상 훈련, 납치나 교전 등의 위기상황 시 대처법, 통금 및 금지구역 숙지, 차량 간격 유지, 현지인 대동 정책, 물자이동 루트의 정기적 변경, 장기 주행 시 통신장비 보유 등 차량운용에 관한 구체적 지침도 마련할 것을 제안하고 있다(Stoddard, Harmer and Ryou 2014).

제 I장

제I장 (good enough) 사이에서 적절한 접점을 찾아 신속하고 유연하게 대처할 것을 권고 한다(Ben Parker 2013). 또한 접근에의 기회가 열렸을 때는 신속한 판단으로 기회를 잘 활용해야 하며, 우선순위를 재설정하는 작업도 신속히 이루어져야 한다.

마지막으로 $\mathrm{UNHCR}$ 의 예시를 통해 한 단체가 인도적 공간의 확보를 위해서 어떠 한 노력을 기울이고 있는지 확인할 수 있다( $\operatorname{Lim} 2011: 25)$. 갈수록 접근이 어려워지 는 분쟁상황에서 UNHCR은 무엇보다 분쟁에 대한 분석을 위한 역량을 강화하고 있 다. 또한 어려운 분쟁상황일수록 정신적·체력적으로 잘 준비가 되어 있는 경험이 풍 부한 직원을 배치하고 있다. 지역사회로 직접 침투하여 협력하는 방식을 통해 인도 적 공간을 확보하려 하고 있으며 윤리적 문제가 생길 수 있는 원격관리는 지양하고 있다. 마지막으로 비정치적인 인도적 기관으로서의 기관의 이미지를 제고함으로써 지역사회에서의 수용도(acceptance)를 높이려는 노력을 기울이고 있다.

현재 ISIS의 상황에서 볼 수 있듯 현대의 분쟁의 양상은 점점 더 복잡해지고 있 다. 적과 아군의 경계가 모호해 지고 있으며 민간인의 희생이 더욱 증가하고 있다. 
이에 따른 인도적 지원의 수요도 급증하고 있으며, 지원활동의 지형도 또한 복잡다 단해지고 있다. 이러한 상황에서 무고한 민간인의 생명을 구조하고 고통을 경감시키 는 숭고한 인도주의의 목적 실현을 가능케 하는 것이 바로 인도적 공간이다. 이 공 간을 확보하기 위해 최선을 다해 준비하고 노력하는 것은 또 다른 민간 구호요원의 희생을 막고 수혜자들의 지원을 받을 권리를 온전히 존중하게 만드는 첫 걸음이라고 도 할 수 있다. 인도적 공간의 중요성은 여기에 있으며 분쟁의 당사자와 인도적 지 원 단체가 이의 확보를 위해 노력해야 할 이유도 여기에 있다. 


\section{참고문헌}

대한적십자사 인도법연구소. 2010. 『무력충돌 희생자 보호에 관한 제네바협 약과 추가의정서』 서울: 대한적십자사 인도법연구소.

Anderson. 1999. Anderson, M. B. (1999). Do no harm. How aid can support peace or war. London: Lynn Rienner Publishers.

Collinson, Sarah \& Samir Elhawary. 2012. "Humanitarian space: a review of trends and issues." London: Overseas Development Institute.

Egeland, Jan, Adele Harmer and Abby Stoddard. 2011. "To stay and deliver: Good practice for humanitarians in complex security environments."

https://docs.unocha.org/sites/dms/Documents/Stay_and_De liver.pdf(검색일: 2014.11.1.)

Gassmann, Pierre. 2005. "Rethinking Humanitarian Security." Humanitarian Exchange Magazine. 30: 32-33.

Hilhorst, Dorothea., \& Jansen, Bram J. 2010. "Humanitarian space as arena: A perspective on the everyday politics of aid." Development and Change 41(6): 1117-1139.

Hubert, Don \& Cynthia Brassard-Boudreau. 2010. "Shrinking humanitarian space? Trends and prospects on security and access." The Journal of Humanitarian Assistance.

Inter-Agency Standing Committee 70th Working Group Meeting. 2008. "Background Document: Preserving Humanitarian Space, Protection and Security." 11-13 March 2008. New York: UNICEF.

IRIN Humanitarian News and Analysis. 2012. "AID POLICY: A "new humanitarianism" at play in Syrian crisis." http://www.irinnews.org/report/95209/aid-policy-a-new-h umanitarianism-at-play-in-syrian-crisis(검색일: 2012.3.30) 
Jackson, Ashley. 2012. "Talking to the Other Side: Humanitarian engagement with armed non-state actors." Humanitarian Policy Group Brief. 47.

Karim, Ataul, Mark Duffield, Suzanne Jaspars, Aldo Benini, Joanna Macrae, Mark Bradbury, Douglas Johnson, George Larbi, and Barbara Hendrie. 1996. "Operation Lifeline Sudan" New York: UN.

Lim, Janet. 2012. "Contemporary Challenges for Humanitarian Engagement in Insecure and Complex Environments." in "Humanitarian Space and the International Community" 16th Humanitarian Conference by Vautravers, Alexandre J. and Yvita Fox. (eds.) (pp.22-27). Geneva: Webster University.

Maxwell, Daniel, Martina Santschi and Rachel Gordon. 2014. "Looking back to look ahead? Reviewing key lessons from Operation Lifeline Sudan and past humanitarian operations in South Sudan." Working Paper 24. London: Secure Livelihoods Research Consortium.

Oxfam International. 2008. "Policy Compendium Note on United Nations Integrated Missions and Humanitarian Assistance." Oxford: Oxfam International.

Parker, Ben. 2013. "Humanitarianism Besieged." Humanitarian Exchange Magazine. 59: 3-5.

Salera, Barbara. 2012. "New Humanitarianism and the Maintenance of Humanitarian Space." in "Humanitarian Space and the International Community" 16th Humanitarian Conference by Vautravers, Alexandre J. and Yvita Fox. (eds.) (pp.53-62). Geneva: Webster University.

Slim, Hugo and Emanuela-Chiara Gillard. 2013. "Ethical and legal perspectives on cross-border humanitarian operations." Humanitarian Exchange Magazine 59: 6-8. 
Steets Julia, Urban Reichhold and Elias Sagmeister. 2012. "Evaluation and review of humanitarian access strategies in DG ECHO funded interventions." Global Public Policy Institute. Berlin.

http://ec.europa.eu/echo/files/evaluation/2012/GPPi_Acces s-Report.pdf

Stoddard, A., Harmer, A., \& Renouf, J. S. (2010). Once removed: Lessons and challenges in remote management of humanitarian operations for insecure areas. Humanitarian Outcomes. New York.

Stoddard, A., Adele Harmer, and Kathleen Ryou. 2014. "Aid Worker Security Report 2014. Unsafe Passage: Road attacks and their impact on humanitarian operations." Washington, DC: USAID.

Tennant, Vicky, Bernie Doyle and Raouf Mazou. 2012. "Safeguarding humanitarian space: A review of key challenges for UNHCR." in "Humanitarian Space and the International Community" 16th Humanitarian Conference by Vautravers, Alexandre J. and Yvita Fox. (eds.) (pp.28-52). Geneva: Webster University.

Terry, Fiona. 2011. "The International Committee of the Red Cross in Afghanistan: reasserting the neutrality of humanitarian action." International Review of the Red Cross. 93(881): $173-188$.

Th rer, Daniel. 2007. "Dunant's pyramid: thoughts on the "humanitarian space". International Review of the Red Cross. 89(865): $47-61$.

UN OCHA. 2003. "Glossary of Humanitarian Terms: In relation to the Protection of Civilians in Armed Conflict." http://un-interpreters.org/glossaries/ocha\%20glossary.pdf (검색일: 2014.11.2) 
Vautravers, Alexandre J. and Yvita Fox. 2011. "Humanitarian Space and the International Community." 16th Humanitarian Conference. Geneva: Webster University Geneva.

Von Pilar, Ulrike. 1999. "Humanitarian Space Under Siege: Some Remarks from an Aid Agency's Perspective." Background paper prepared for the Symposium "Europe and Humanitarian Aid

- What Future? Learning from Crisis", 22-23 April 1999 in Bad Neuenahr.

\section{-News Articles}

Al Jazeera. 2009. "Al Jazeera Red Cross Visits Taleban Captives: Humanitarian organisation given access to three people held in Afghanistan.”

http://www. aljazeera.com/news/asia/2009/12/200912166173 0958514.html(검색일: 2013.1.5.)

ICRC. 2007. "Afghanistan: Promoting dialogue through neutrality." 27-09-2007 Interview.

http://www.icrc.org/eng/resources/documents/interview/af ghanistan-interview-210907.htm(검색일: 2014.11.1.)

ICRC. 2009. "Afghanistan: ICRC maintains neutral, independent, humanitarian assistance." 06-11-2009 Interview.

http://www.icrc.org/eng/resources/documents/interview/af ghanistan-interview-061109.htm(검색일: 2014.11.1.)

ICRC. 2010. "Afghanistan: ICRC Defends First Aid Training for Taliban." 2010. 5. 26. Agence France-Presse (검색일: 2014.11.1.) 